\title{
Xanthogranulomatous pancreatitis combined with multifocal necrosis: A case report and literature review
}

\author{
Xuemei Tang, MDa, Wenming Lu, MD ${ }^{\mathrm{b}, \star}$
}

\begin{abstract}
Xanthogranulomatous inflammation is rare and occurs in several viscera in the body, such as the kidney, gallbladder, bone, and stomach. The pathogenesis of Xanthogranulomatous pancreatitis (XGP) is not well understood, and the disease is characterized by lipid-laden histiocytes deposited at various sites in the organs. XGP associated with multifocal necrosis is extremely rare. In this report, we described a case of XGP associated with multifocal necrosis and included a review of the literature.
\end{abstract}

Keywords: Pancreas, Xanthogranulomatous, Inflammation

Xanthogranulomatous inflammation is rare circumstance in which lipid-laden histiocytes are deposited at various sites in the organs. Xanthogranulomatous pancreatitis (XGP) combined with multifocal necrosis is extremely rare. We report a case of XGP with multifocal necrosis. To our knowledge, 2 cases in China have been published in Chinese journals. This is the first reported case in China in the English-language literature.

\section{Case presentation}

A 76-year-old man was referred to our hospital (Huzhou First People's Hospital, Huzhou, China) for further examination of persistent upper abdominal pain associated with vomiting of stomach contents after eating that lasted for 2 weeks. The patient reported that his weight was unchanged over the past 3 months. $\mathrm{He}$ had upper abdomen tenderness through physical examination. There was no history of fever, chills, or chest pain. His medical and surgical history was unremarkable except for hypertension without controlled. His social history was unremarkable. His carbohydrate antigen 125 (CA125) was elevated to $40.5 \mathrm{U} / \mathrm{mL}$, serum lipase was

\footnotetext{
aDepartment of Ultrasound, The Affiliated Hospital of North Sichuan Medical College, Nanchong, Sichuan and ${ }^{b}$ Department of Ultrasound, Huzhou First People's Hospital, Huzhou, Zhejiang, P.R. China

This case has reported work in accordance with SCARE 2018 standards. This manuscript has been peer reviewed.

Sponsorships or competing interests that may be relevant to content are disclosed at the end of this article.

*Corresponding author. Address: Department of Ultrasound, Huzhou First People's Hospital, Huzhou, Zhejiang 313000, P.R. China. Tel: + 86 13957242240; fax: 05722039401. E-mail address: 13957422240@163.com (W. Lu).

Copyright (C) 2021 The Authors. Published by Wolters Kluwer Health, Inc. on behalf of IJS Publishing Group Ltd. This is an open access article distributed under the

Creative Commons Attribution License 4.0 (CCBY), which permits unrestricted use, distribution, and reproduction in any medium, provided the original work is properly cited.

International Journal of Surgery Oncology (2021) 5:e101

Received 4 August 2020; Accepted 30 August 2020

Published online 27 January 2021

http://dx.doi.org/10.1097//J9.0000000000000101
}

elevated to $148.6 \mathrm{UL}$, and serum amylase was $100 \mathrm{UL}$ (high normal). Total protein was reduced to $64.8 \mathrm{~g} / \mathrm{L}$, and albumin was reduced to $36.9 \mathrm{~g} / \mathrm{L}$. Other laboratory data, including serum carcinoembryonic antigen, carbohydrate antigen 19-9, CA153, C-reactive protein, bilirubin, and leukocytes, were normal. Abdomen 2-dimensional ultrasound revealed a $75 \mathrm{~mm} \times 60 \mathrm{~mm}$ homogeneous hypoechoic mass in the uncinate process of the pancreas (Fig. 1A). Double contrast-enhanced ultrasound (DCEUS) with oral contrast-enhanced ultrasound agents and intravenous contrast-enhanced ultrasound (CEUS) agents were given to the patient at the same time. The peripheral mass began to undergo rapid high enhancement at $20 \mathrm{~s}$ before the pancreas parenchyma (Fig. 1B). Microbubbles in the mass began to wash out at $36 \mathrm{~s}$ (Fig. 1C). Part of the mass did not enhance over time. The size of the mass was calculated as $8.5 \mathrm{~cm} \times 6.7 \mathrm{~cm}$ after enhancement. The duodenum wall was thick around the mass, enhanced and washed out at the same time as the distal wall. There were lymph nodes above 3 around the mass. Based on our experience and the rich microvasculature revealed by CEUS imaging, we inferred that what occurred at the duodenal wall was similar to edema and not a malignant neoplasm infilitration; however, the properties of the mass were uncertain. An abdominal computed tomography (CT) scan demonstrated that the lesion was strongly associated with liquefaction in the pancreatic parenchyma and distinction from the duodenum (Fig. 2A). Contrast-enhanced CT revealed that the mass had irregular ring enhancement and was likely a malignant tumor (Figs. 2B, C).

The mass was obtained by biopsy through ultrasonic guidance, and the pathology result was pancreatic parenchyma chronic inflammation associated with fibrous tissue hyperplasia and multifocal necrosis (Fig. 3A). Whipple's operation (pancreaticoduodenectomy) was performed, and a yellow lump lesion was found to be $8.5 \times 6.0 \mathrm{~cm}$ in size (Fig. 3B). On gross examination, the mass had an unclear border and adhered to the partial transverse mesocolon, greater omentum, and duodenal mesocolon. Microscopically, the lesion was composed of an aggregation of several foam cells, lymphocytes, and multinucleated giant cells as well as necrosis (Fig. 3C). The final diagnosis of XGP associated with multifocal necrosis was made. On postoperative day 20 , the hemodynamics was stabilized, no gastrointestinal hemorrhage, and the patient was extubated. The patient was subsequently discharged. After 6 months, the patient did 

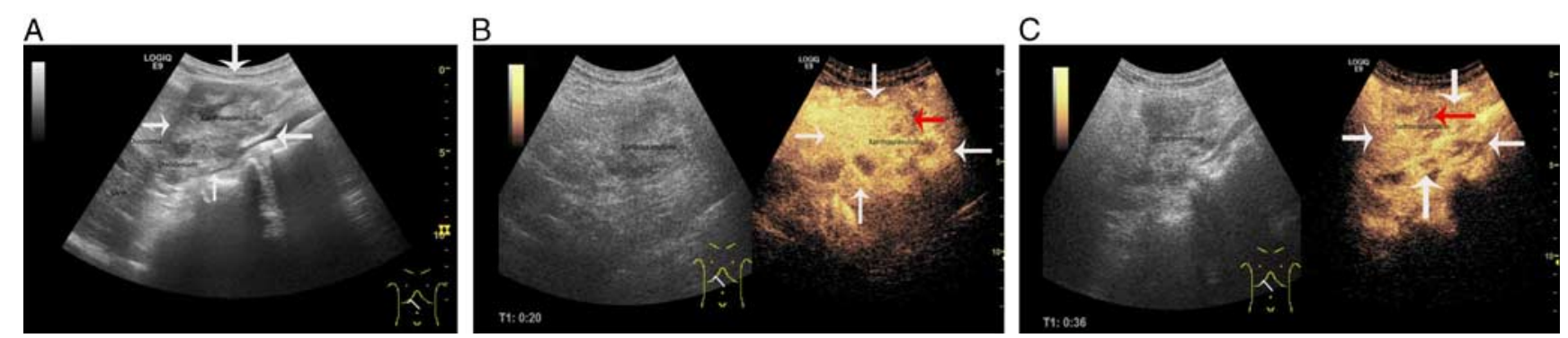

Figure 1. Images of the pancreatic lesions. A, Gray-scale US: the mass was homogeneously hypoechoic in the uncinate process of the pancreas (arrows) and closely related to the duodenum; the border was unclear. B, Enhancement phase (20 s): enhancement started from the edge of the mass (white arrow). C, Regression phase (36 s): the mass began to wash out (white arrows), and the area was not enhanced at all times (red arrow).
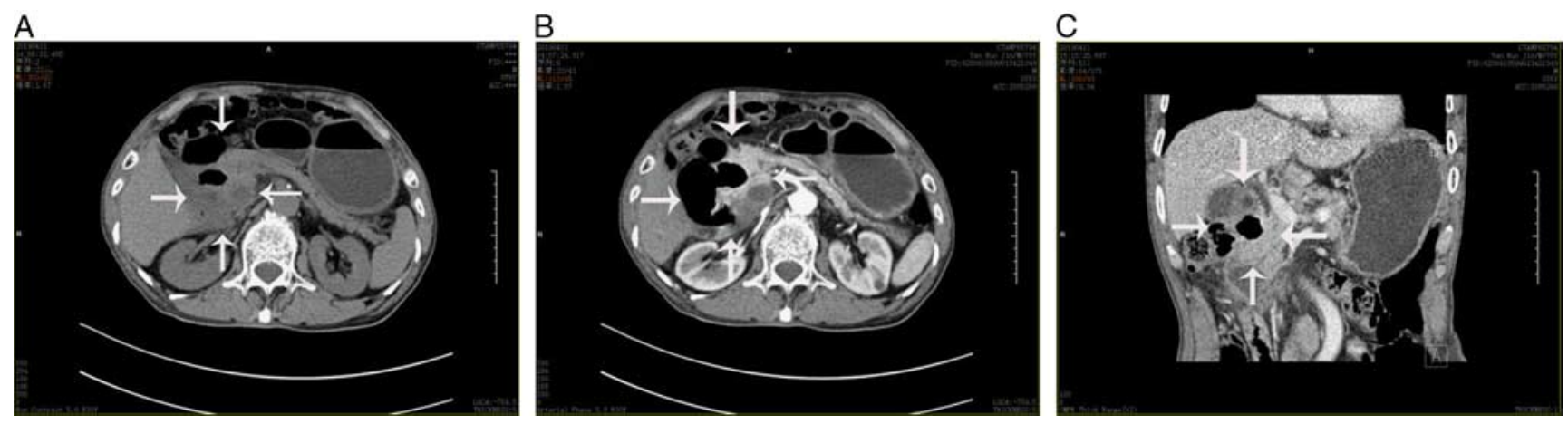

Figure 2. A, Computed tomography (CT) plain scan: solid mass associated with liquefaction in the pancreatic parenchyma. B, Contrast-enhanced CT (cross section of abdomen): the mass was a ring of irregular enhancement, and the cyst area had not enhanced. C, Contrast-enhanced CT (sagittal position): the mass was closely related to the duodenum. The arrows are CT manifestations of the mass.

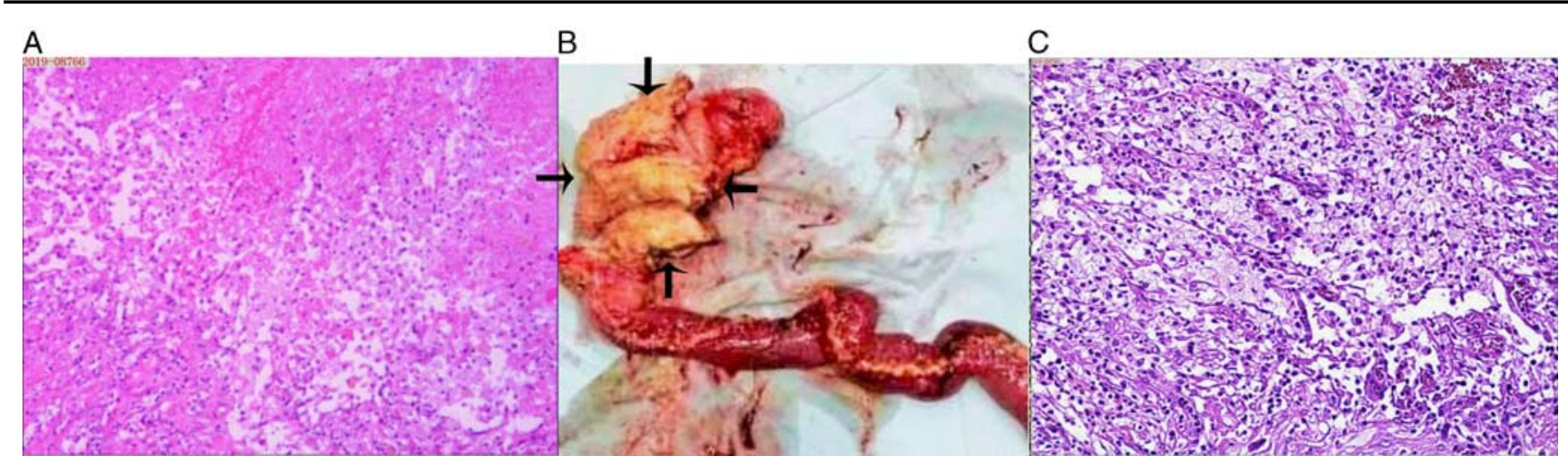

Figure 3. A, Light microscopic examination: showing lymphocytes, fibrous tissue hyperplasia and multifocal necrosis [hematoxylin and eosin (HE) staining; magnification, $\times 100]$. B, Pathologic gross specimens: a yellow nodular lesion (arrows) was found, with adherence to duodenum. C, Light microscopic examination for gross specimens: the mass contained an aggregation of foamy histiocytes, lymphocytes, and plasma cell granulocyte cells (HE staining; magnification, $\times 100)$. 


\section{Table 1}

Imaging and clinical features of Xanthogranulomatous pancreatitis.

\begin{tabular}{|c|c|c|c|c|c|c|c|c|c|c|c|c|c|}
\hline $\begin{array}{l}\text { Case First/ } \\
\text { References }\end{array}$ & $\begin{array}{l}\text { Sex/ } \\
\text { Age (y) }\end{array}$ & Symptom & Country & Site & SIR & $\begin{array}{l}\text { Tumor } \\
\text { markers }\end{array}$ & US & Ст & MRI & $\begin{array}{l}\text { Preoperative } \\
\text { diagnosis }\end{array}$ & Appearance & Operation & $\begin{array}{l}\text { Tumor size } \\
\text { (cm) }\end{array}$ \\
\hline $\begin{array}{l}\text { Uneo et al }{ }^{[5]} \\
\text { lyer et al }{ }^{[6]}\end{array}$ & $\begin{array}{l}42 / M \\
50 / M\end{array}$ & $\begin{array}{l}\text { Abdominal pain } \\
\text { Jaundice }\end{array}$ & $\begin{array}{l}\text { American } \\
\text { India }\end{array}$ & $\begin{array}{l}\text { Body } \\
\text { Head }\end{array}$ & $\begin{array}{c}\mathrm{CRP}+ \\
\mathrm{NA}\end{array}$ & $\overline{\mathrm{NA}}$ & $\begin{array}{l}\text { Homogeneous echotexture } \\
\text { NA }\end{array}$ & $\begin{array}{l}\text { Hypoattenuating } \\
\text { NA }\end{array}$ & $\begin{array}{c}\downarrow T 1, \uparrow T 2 \\
N A\end{array}$ & $\begin{array}{l}\text { Pseudo cyst } \\
\text { Malignancy }\end{array}$ & $\begin{array}{l}\text { Cystic } \\
\text { Nodular }\end{array}$ & $\begin{array}{c}\text { DP } \\
\text { Mass } \\
\text { excision }\end{array}$ & $\begin{array}{c}8 \times 5 \\
3\end{array}$ \\
\hline lyer et al ${ }^{[6]}$ & $36 / M$ & Stone & India & Tail & NA & NA & NA & NA & NA & Malignancy & Massive & $\mathrm{DP}+\mathrm{S}+\mathrm{PG}$ & NA \\
\hline Kamitani et al ${ }^{[7]}$ & $82 / \mathrm{M}$ & Epigastric pain & Japan & Body & - & - & NA & $\begin{array}{l}\text { III-defined } \\
\text { enhancing }\end{array}$ & $\downarrow T 1, \uparrow T 2$ & IPMT & Cystic & $\mathrm{DP}+\mathrm{S}+\mathrm{PG}$ & $3 \mathrm{~cm}$ \\
\hline $\begin{array}{l}\text { Okabayshi } \\
\text { et a } \mathrm{I}^{[12]}\end{array}$ & 60/M & $\begin{array}{l}\text { Abdominal pain and } \\
\text { pancreatic cystic mass }\end{array}$ & Japan & Tail & $\mathrm{CRP}+$ & - & NA & Hypoattenuating & NA & Pseudo cyst & Cystic & DP & NA \\
\hline $\begin{array}{l}\text { Okabayshi } \\
\text { et a }{ }^{[12]}\end{array}$ & 69/M & Abdominal pain & Japan & Tail & $\mathrm{CRP}+$ & - & NA & Hypoattenuating & NA & Pseudo cyst & Cystic & DP & NA \\
\hline Shima et al ${ }^{[13]}$ & $66 / M$ & Epigastric pain & Japan & Body & $\mathrm{CRP}+$ & CA199+ & NA & Hypoattenuating & $\begin{array}{l}\text { Isointense } \\
\mathrm{T} 1, \uparrow T 2\end{array}$ & Malignancy & Solid & DP & 4 \\
\hline Iso et al ${ }^{[9]}$ & 82/M & Weight loss & Japan & Tail & $\mathrm{CRP}+$ & - & Heterogeneous echotexture & Hypoattenuating & NA & IPMC & Nodular & $\mathrm{DP}$ & NA \\
\hline |keura et al| ${ }^{[14]}$ & 73/M & Abdominal pain & Japan & Body & - & - & $\begin{array}{l}\text { Heterogeneous (mostly } \\
\text { solid, partially cystic) }\end{array}$ & Hypoattenuating & Mildly $\uparrow T 1$ & SPPT & Cystic & PPPD & $4 \times 4$ \\
\hline Uguz et al ${ }^{[15]}$ & $30 / M$ & Abdominal pain & Turkey & Head & - & - & NA & NA & NA & $\begin{array}{c}\text { Chronic } \\
\text { pancreatitis }\end{array}$ & NA & DPP & NA \\
\hline Uguz et al ${ }^{[15]}$ & $34 / F$ & Abdominal pain & Turkey & Head & - & - & NA & NA & NA & $\begin{array}{c}\text { Chronic } \\
\text { pancreatitis }\end{array}$ & NA & DPP & NA \\
\hline Kim et al ${ }^{[16]}$ & $72 / F$ & Abdominal pain & Korea & Body & - & - & NA & NA & $\begin{array}{l}\text { Subtle, } \\
\text { focalıT1 }\end{array}$ & IPMT & Cystic & PPPD & $1.5 \times 1$ \\
\hline Kim et al ${ }^{[4]}$ & $70 / F$ & Abdominal pain & Korea & Head & $\mathrm{CRP}+$ & - & NA & Hypoattenuating & $\begin{array}{l}\text { Isointense } \\
\mathrm{T} 1, \uparrow T 2\end{array}$ & Malignancy & Solid & WPD & $2.2 \times 2.0$ \\
\hline $\begin{array}{l}\text { Nishmimura } \\
\text { et al }{ }^{[17]}\end{array}$ & $76 / \mathrm{M}$ & Abdominal pain, Weight loss & Japan & Body & $\begin{array}{l}\text { White blood } \\
\text { cell + }\end{array}$ & - & NA & $\begin{array}{l}\text { Cystic lesion, thick } \\
\text { wall }\end{array}$ & $\downarrow T 1, \uparrow T 2$ & IPMC & Cystic & $\mathrm{DP}+\mathrm{S}$ & $5.2 \times 2.6$ \\
\hline $\begin{array}{l}\text { Atreyapurapu } \\
\text { et al }{ }^{[18]}\end{array}$ & 60/M & Abdominal pain & India & Head & Normal & Normal & NA & Heterogeneously & NA & Malignancy & Solid & WPD & NA \\
\hline Hanna et al ${ }^{[19]}$ & $50 / F$ & Abdominal pain and nausea & UK & $\begin{array}{l}\text { Body/ } \\
\text { tail }\end{array}$ & $\mathrm{CRP}+$ & $\begin{array}{l}\text { CA199 + } \\
\text { CEA + }\end{array}$ & NA & Hypoattenuating & NA & Malignancy & Cystic & DP & $14 \times 14 \times 14.5$ \\
\hline$K_{w o n}^{[20]}$ & $60 / M$ & Pancreas MASS & Korea & Body & - & CEA + & NA & Low-attenuated & $\downarrow T 1, \uparrow \top 2$ & uncertain & Solid & DP & $1.6 \times 1.5$ \\
\hline Navarro et al ${ }^{[10]}$ & $86 / F$ & $\begin{array}{l}\text { Epigastric pain and weight } \\
\text { loss }\end{array}$ & Spanish & Head & - & - & Heterogeneous & $\begin{array}{l}\text { Hypermetabolic } \\
\text { nodule }\end{array}$ & $\mathrm{N} / \mathrm{A}$ & Malignancy & Solid & conservative & NA \\
\hline Becker et a ${ }^{[21]}$ & $56 / \mathrm{M}$ & Prostate adenocarcinoma & American & Tail & - & $\mathrm{CEA}+$ & Heterogeneously hypoechoic & Hypoattenuating & $\downarrow T 1, \uparrow T 2$ & IPMN & Cystic & $\mathrm{DP}+\mathrm{S}$ & $2.8 \times 2.5$ \\
\hline Gaur et al ${ }^{[22]}$ & $58 / \mathrm{M}$ & $\begin{array}{l}\text { Abdominal pain and weight } \\
\text { loss }\end{array}$ & India & Head & $\mathrm{CRP}+$ & $\begin{array}{l}\text { CA199+ } \\
\text { CEA + }\end{array}$ & Solid cystic lesion & $\begin{array}{l}\text { Heterogeneously } \\
\text { enhancing }\end{array}$ & NA & Malignancy & $\begin{array}{l}\text { Solid and } \\
\text { cystic }\end{array}$ & WPD & $6.1 \times 5.2 \times 4.0$ \\
\hline Present case & $76 / M$ & Abdominal pain, vomiting & China & Head & - & $\mathrm{CA} 125+$ & $\begin{array}{l}\text { Mostly solid, partially cystic; } \\
\text { ringed enhanced }\end{array}$ & $\begin{array}{l}\text { Irregular } \\
\text { enhancing }\end{array}$ & NA & Malignancy & Solid & $W P D+P G$ & $8.5 \times 6.0$ \\
\hline
\end{tabular}


not experience any recurrence. This case is reported in accordance with the SCARE 2018 standard $^{[1]}$.

\section{Discussion}

Xanthogranulomatous changes are considered a rare chronic inflammation characterized by an aggregation of foamy histiocytes and inflammatory cells. The lesion has been reported in various cases in the gallbladder and kidney ${ }^{[2]}$. According to one proposed etiology for xanthogranulomatous cholecystitis, bile enters the gallbladder wall and is engulfed by macrophages, resulting in a chronic granulomatous inflammatory response $^{[3]}$. The etiology of XGP is not entirely clear but likely results from a combination of duct obstruction, infection, and repeated hemorrhage, as is seen in the kidney and gallbladder ${ }^{[4-7]}$. Xanthogranulomatous lesions in the pancreas are a benign condition. Kwon et $\mathrm{al}^{[8]}$ concluded the lesion was a progressive enhancement pattern in contrast-enhanced CT and MRI with 10 cases. PET/CT examinations showed focal hypermetabolism, which was one of the diagnostic impressions of pancreatic cancer on PET/CT ${ }^{[8]}$. XGP manifests neoplasmlike characteristics, such as being poorly defined with local tissue invasion and destruction ${ }^{[7,9]}$. It is difficult to discriminate this condition from pancreatic cancer with clinical and radiologic results[9]. As a result, most cases were overtreated with surgical resection, and there have been only 2 reported cases of conservative management following a nonoperative diagnosis $^{[10,11]}$.

Twenty-one cases had been reported in English literature before 2019.A review of the existing literature was performed (Table 1). All cases were mostly from Asian countries, especially Japan (15/21). The patient age was 61.3 years (range, 30-86 y), and most were men (16/21). They were referred to the hospital for epigastric pain (16/21), accompanied by weight loss in 4 cases. Some patients with an inflammatory response had an elevated white blood cell count or elevated C-reactive protein (9/19). The lesions appeared hypointense on T1-weighted images and hyperintense on T2-weighted images (5/9) in which MRI examination was performed. Contrast-enhanced CT showed that the lesion was hypoattenuating (10/16). The result of 2-dimensional ultrasound was homogeneous echotexture (5/7), and most cases had no CEUS examination performed. The preoperative diagnosis in 15 cases (15/21) was malignancy. Of all cases, 2 cases underwent conservation treatment, and the others (included ours) were treated with surgery. In our case, the lesion was large because the patient had not been examined previously. The mass was solid and was associated with liquefaction in the pancreatic parenchyma and a ring of irregular enhancement with an indefinite border on CT scan in our case. DCEUS showed that the lesion was enhanced before the pancreatic parenchyma, and part of the lesion had no enhancement at all times; thus, we thought it was necrotic. It was also noteworthy that the duodenal wall manifested as inflammatory edema and not tumor infiltration. Based on the above information, we concluded that a malignant lesion could not be excluded. However, we did not perform other imaging, such as MRI and PET scans, as we had shunted the lesion. To alleviate the severe symptoms of the patient, we decide to explore abdominal cavity. During the exploration, we found a solid mass with a diameter of about $8 \mathrm{~cm}$ at the level of the uncinate process of the pancreas, the boundary of which was unclear, and part of the transverse mesocolon, omentum, and duodenum were involved and densely adhered, so we performed a Whipple's operation.

\section{Conclusions}

Although XGP associated with multifocal necrosis is rare, it is important for surgeons, pathologists and radiologists to recognize this uncommon entity, as the lesion may manifest clinical features that mimic those of pancreatic tumors.

\section{Ethical approval}

Written informed consent for publication was obtained from the patient.

\section{Source of funding}

None.

\section{Author contribution}

X.T. and W.L. contributed the same to this article. They contributed to write the manuscript, to gather the clinical data as well as the relevant imaging information. All authors read and approved the final manuscript.

\section{Conflict of interest disclosure}

The authors declare that they have no financial conflict of interest with regard to the content of this report.

\section{Research registration unique identifying number (UIN)}

Not applicable.

\section{Guarantor}

Xuemei Tang.

\section{References}

[1] Agha RA, Borrelli MR, Farwana R, et al. The SCARE 2018 statement: updating consensus Surgical CAse REport (SCARE) guidelines. INT J SURG 2018;60:132-6.

[2] Guzman-Valdivia G. Xanthogranulomatous cholecystitis: 15 years' experience. World J Surg 2004;28:254-7.

[3] Suzuki H, Wada S, Araki K, et al. Xanthogranulomatous cholecystitis: difficulty in differentiating from gallbladder cancer. World J Gastroenterol 2015;21:10166-73.

[4] Kim HS, Joo M, Chang SH, et al. Xanthogranulomatous pancreatitis presents as a solid tumor mass: a case report. J Korean Med Sci 2011;26:583-6.

[5] Ueno T, Hamanaka Y, Nishihara K, et al. Xanthogranulomatous change appearing in the pancreas cyst wall. Pancreas 1993;8:649-51.

[6] Iyer VK, Aggarwal S, Mathur M. Xanthogranulomatous pancreatitis: mass lesion of the pancreas simulating pancreatic carcinoma-a report of two cases. Indian J Pathol Microbiol 2004:47:36-8.

[7] Kamitani T, Nishimiya M, Takahashi N, et al. Xanthogranulomatous pancreatitis associated with intraductal papillary mucinous tumor. AJR Am J Roentgenol 2005;185:704-7. 
[8] Kwon JH, Kim JH, Kim SY, et al. Imaging and clinical features of xanthogranulomatous pancreatitis: an analysis of 10 cases at a single institution. Abdom Radiol (NY) 2018;43:3349-56.

[9] Iso Y, Tagaya N, Kita J, et al. Xanthogranulomatous lesion of the pancreas mimicking pancreatic cancer. Med Sci Monit 2008;14:S130-3.

[10] Navarro NB, Saez GE, Ortuno JA. Xanthogranulomatous pancreatitis: a lesion that mimics pancreatic cancer. Rev Esp Enferm Dig 2017;109:234.

[11] Park JM, Cho SH, Bae HI, et al. Xanthogranulomatous pancreatitis mimicking a pancreatic cancer on CT and MRI: a case report and literature review. Investig Magn Resonance Imaging 2016;20:185-90.

[12] Okabayashi T, Nishimori I, Kobayashi M, et al. Xanthogranulomatous pancreatic abscess secondary to acute pancreatitis: two case reports. Hepatogastroenterology 2007;54:1648-51.

[13] Shima Y, Saisaka Y, Furukita Y, et al. Resected xanthogranulomatous pancreatitis. J Hepatobiliary Pancreat Surg 2008;15:240-2.

[14] Ikeura T, Takaoka M, Shimatani M, et al. Xanthogranulomatous inflammation of the peripancreatic region mimicking pancreatic cystic neoplasm. Intern Med 2009;48:1881-4.

[15] Uguz A, Yakan S, Gurcu B, et al. Xanthogranulomatous pancreatitis treated by duodenum-preserving pancreatic head resection. Hepatobiliary Pancreat Dis Int 2010;9:216-8.
[16] Kim YN, Park SY, Kim YK, et al. Xanthogranulomatous pancreatitis combined with intraductal papillary mucinous carcinoma in situ. J Korean Med Sci 2010;25:1814-7.

[17] Nishimura M, Nishihira T, Hirose T, et al. Xanthogranulomatous pancreatitis mimicking a malignant cystic tumor of the pancreas: report of a case. Surg Today 2011;41:1310-3.

[18] Atreyapurapu V, Keshwani A, Lingadakai R, et al. Xanthogranulomatous pancreatitis mimicking a malignant solid tumour. BMJ Case Rep 2016; 2016:1-3.

[19] Hanna T, Abdul-Rahman Z, Greenhalf W, et al. Xanthogranulomatous pancreatitis associated with a mucinous cystic neoplam. Pathol Int 2016; $66: 174-6$.

[20] Kwon HJ. Xanthogranulomatous pancreatitis mimicking potentially malignant pancreatic neoplasm: report of a case. Ann Hepatobiliary Pancreat Surg 2017;21:243-6.

[21] Becker-Weidman D, Flore B, Mortele KJ. Xanthogranulomatous pancreatitis: a review of the imaging characteristics of this rare and often misdiagnosed lesion of the pancreas. Clin Imaging 2017;45:12-7.

[22] Gaur K, Mandal S, Mahajan N, et al. Xanthogranulomatous pancreatitis-a rare case defying clinical, radiological and tumor marker diagnostics with a review of literature. Turk Patoloji Derg 2019;35:144-50. 